\title{
Combined parallel and K-T approach improves dynamic imaging
} Geetha Rayarao*, Vikas K Rathi, June A Yamrozik, Ronald B Williams, Diane A Vido, Saundra B Grant, Robert W Biederman and Mark Doyle

\author{
Address: The Center for Cardiovascular Magnetic Resonance Imaging, The Gerald McGinnis Cardiovascular Institute at Allegheny General \\ Hospital, Pittsburgh, PA, USA \\ * Corresponding author
}

from I3th Annual SCMR Scientific Sessions

Phoenix, AZ, USA. 21 -24 January 2010

Published: 21 January 2010

Journal of Cardiovascular Magnetic Resonance 2010, I 2(Suppl I):P82 doi:I0.I 186/1532-429X-I2-SI-P82

This abstract is available from: http://jcmr-online.com/content/I2/SI/P82

(c) 2010 Rayarao et al; licensee BioMed Central Ltd.

\section{Introduction}

Previously we introduced the k-space-time (KT) acceleration approach MACH (Multiple Acceleration Hierarchy) and the parallel imaging variant SCIPI (Single Coil Implementation of Parallel Imaging). While KT approaches retain signal to noise, high acceleration values result in temporal blur, and conversely parallel approaches result in loss of SNR and introduce non-cancellation artifacts. It is not known for MACH and SCIPI what combination results in lower artifacts.

\section{Purpose}

We hypothesize that for progressively higher resolution scans, higher accelerations can be achieved with low artifact by the combination of MACH and SCIPI (Combo).

\section{Methods}

Fully resolved cine images (SSFP, TR/TE 4.1/2.1) with a matrices of 224, 336 and 384 were used to simulate $\mathrm{MACH}$ and SCIPI with acceleration factors ranging from 2-15. A uniform cardiac region was compared between the original images and accelerated scans to assess the net error term. For each resolution series (224, 336 and 384), a line was fitted for error term vs. acceleration separately for $\mathrm{MACH}$ alone and the Combo.

\section{Results}

For each series, the fitted lines describing the error term vs. acceleration for $\mathrm{MACH}$ alone and Combo intersected to reveal a point where Combo quality exceeded MACH alone. For all series, above this point, the Combo quality was higher than that of MACH. The acceleration values at the transition point for each series were 2, 5 and 8 for resolutions 224, 336 and 384, respectively. These intersection points were in turn fitted to a straight line with the formula: Resolution $=26.7 \times$ acceleration +181 . For example, it indicates that at a resolution of 512, MACH would be beneficial up to an acceleration of 12 , and Combo would be better after that. In figure 1 , the results for 336 resolution comparing the original (A), MACH (B) vs. Combo (C), both with acceleration 8 are shown, indicating the superiority of the Combo series.

\section{Conclusion}

When using accelerated scans relying on KT and parallel approaches, higher accelerations generally benefit from a combination of the two. Here we showed that the acceleration transition point linearly increases with spatial resolution. In general, when high accelerations are required for cine imaging, the combination of a moderate acceleration for each of the two approaches is superior to applying the KT or parallel approaches singly. 


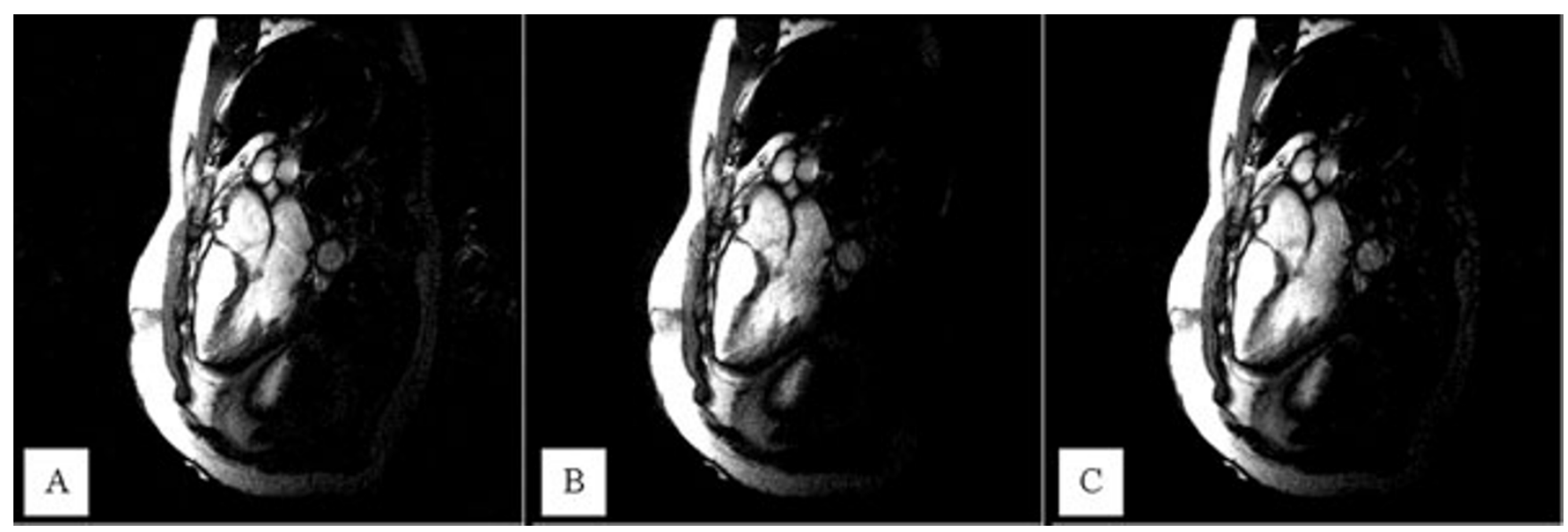

Figure I

Publish with Biomed Central and every scientist can read your work free of charge

"BioMed Central will be the most significant development for disseminating the results of biomedical research in our lifetime. "

Sir Paul Nurse, Cancer Research UK

Your research papers will be:

- available free of charge to the entire biomedical community

- peer reviewed and published immediately upon acceptance

- cited in PubMed and archived on PubMed Central

- yours - you keep the copyright 